Down Syndrome Research and Practice Vol 5, No.2, 53 - 62.

(C) The Down Syndrome Educational Trust

Printed in Great Britain. All rights reserved.

ISSN: 0968-7912 (1998) 5:2

\title{
PRELINGUISTIC COMMUNICATION AND DOWN SYNDROME
}

\author{
Brickchand Ramruttun and Christine Jenkins \\ University of Portsmouth, UK
}

\begin{abstract}
The goal of this study was to examine the prelinguistic communication skills of children with Down syndrome. Ten children with Down syndrome, ten nondelayed children and five children with learning disabilities but not Down syndrome were matched for one word comprehension level on the Derbyshire Language Scheme (Masidlover \& Knowles, 1982). Data was gathered by completing the "Pragmatics Profile of Early Communication Skills" (Dewart \& Summers, 1988) and by making ten minute samples of video recordings of mother and child engaged in low structured free play situations. Results and preliminary analyses showed that there was no significant difference in the extent to which children with Down syndrome use most non-verbal communicative behaviours compared to non-delayed infants when matched for comprehension. However, they were significantly delayed at using referential eye contact and words. These results and the issue of whether they are specific to children with Down syndrome are discussed in the light of contemporary findings.
\end{abstract}

Keywords: Down syndrome, communication, non-verbal communication, infants

\section{Introduction}

Communication is a highly complex and dynamic phenomenon whereby the message sender and receiver are continuously co-ordinating and modifying their present and anticipated actions according to each others signals (Fogel, 1993). It is multimodal and multidimensional in nature. Prelinguistic communication refers to the rich interpersonal, intentional, meaningful and essentially non-linguistic communication that characterises early face to face interactions between infants and their care givers.

The field of infants' communicative development has been informed by a variety of distinct theoretical perspectives over almost four decades. The Skinnerian behavioural approach which emphasised the role of operant conditioning, (Skinner, 1957) has been heavily criticised by Chomsky (1959) who advocates a nativist theory. The basic tenet of this is that communication and language development is made possible by infants' possession of an innate language acquisition device (LAD), thus denying the contribution of the environment to this process.

Fodor (1983) argues that language development is the responsibility of one of a set of distinct modules of which the mind is composed. On the other hand, several researchers have attributed communicative development initially to growth in general cognitive capacities and later to more specific cognitive developments (Bates Camaioni \& Volterra 1975)

The sociolinguistic approach, owing its origin to the Vygotskian concept of the "zone of proximal development", (Vygotsky, 1986) advocates an interactional / transactional model of communicative development. Bruner (1983), in support suggests that a sensitive environment acts as a 'language acquisition support system' (LASS) which 'scaffolds' the child's development.

Although several studies have found positive correlations for all these contradictory 
hypotheses, the latter approach has received more support than most. This rich theoretical framework has been useful in explaining both impaired and typical communicative development.

\section{Prelinguistic communication development}

Early research into the language learning difficulties of children with Down syndrome have been preoccupied with whether it is different or delayed (Lenneberg, 1967). The "delay" position describes the development of children with Down syndrome as slow but essentially similar to that of typical infants which according to Rondal (1985) is true for broad outlines of their linguistic development. However, when other components of language such as pragmatics, syntax and semantics are considered some aspects are more delayed than others thus supporting the developmental deviance position (Rondal, 1985). Rondal concludes that "no complete dichotomy exists between delay and difference" (p. 324).

\section{Looking behaviour}

Amongst the early infant behaviours, looking has been described as one of the most important (Robson, 1967). The visual acuity of most infants with Down syndrome at birth is known to be within the normal range (Woodhouse et al, 1996) but from about 2 years of age it is said to deteriorate even when "refractive errors" are controlled for (Courage et al, 1994). Three to 14 month old infants with Down syndrome are also found to have significant difficulties in accommodation (Woodhouse et al, 1996).

Fantz, Fagan and Miranda (1975) have established that the development of visual preference for and recognition of faces is delayed in children with Down syndrome. Eye contact is said to emerge at 6.7 weeks, compared to 4.1 weeks for non-delayed infants (Berger, 1980) and it peaks later too at about 4-5 months (Berger, 1990). By this age, gaze duration of infants with Down syndrome is significantly higher than that of MA matched non-delayed infants (Jones, 1977; Berger, 1980). This gives rise to delays in visual exploring (Berger, 1980). Jones (1977) reports significantly lower levels of referential eye contact amongst older infants with Down syndrome.

\section{Smiling}

Smiling is an expression of the infant's positive affect which is innate in origin. Its onset in infants with Down syndrome is delayed by 5 weeks compared to non-delayed babies (Berger \&
Cunningham, 1986). Initially, it is also shorter in duration and weaker in expression (Buckhalt et al, 1978; Berger, 1980). It has been argued that infants with Down syndrome have a neutral response style caused by lower levels of arousal (Kasari et al, 1990).

Knieps et al. (1994) add that MA matched (1223 months) toddlers with Down syndrome have more difficulties matching their affective expressions to those of their parents compared to non-delayed infants. They otherwise report no significant differences in the lability, intensity and neutrality of the affective responsiveness of these infants within a social referencing situation. Later smiling development of infants with Down syndrome is said to follow a "normal" course. For instance, their smiling is often "temporally associated with episodes of eye contact" (Berger, 1980 p.117).

\section{Vocalisation}

The development of early babbling in infants with Down syndrome is mostly similar to that of non-delayed children (Smith \& Oller, 1981) particularly the age of onset, frequency, length and type (Dodd, 1972). Lynch et al (1995) contradict the above by stating that the onset of cannonical babbling in infants with Down syndrome is 'less stable' than that of non-delayed children. They suggest that this babbling in infants with Down syndrome emerges at around 9 months of age showing a delay of 2 months from the norm.

There is no age related decrease in vocalisation at about 8 months (Berger \& Cunningham, 1983) as evidenced in non-delayed children. Vocal imitation is delayed too (Mahoney et al, 1981). Jones (1977) argues that older infants with Down syndrome tend to vocalise in a continuous string thus making interactions and communication with their mothers rather difficult.

Furthermore, Lynch et al (1995) suggest that delays in early vocal development in infants with Down syndrome may be contributing to their communication difficulties as confirmed by a significant negative correlation between measures on the Early Social Communication Scale at 27 months and home onset cannonical babbling.

\section{Social interaction}

Sociolinguists regard social interactions as the main foundation of communicative development (Schaffer, 1984 \& Bruner, 1983 amongst others). Infants with Down syndrome are less likely to initiate and maintain interactions with their 
mothers than their MA matched non-delayed peers (Jones, 1977). Face to face visual interactions and explorations are also said to be delayed as a result of prolonged and fixated eye contacts (Berger, 1980; Jones, 1977). During vocal interactions with their mothers, they often have difficulty taking turn thus resulting in 'vocal clashes' (Jones, 1977).

These interactional difficulties, which tend to persist in older children with Down syndrome (Berger \& Cunningham, 1983) have been known to be attributed to a more directional maternal style (Sorce \& Emde, 1982). “...... high levels of maternal stimulation and poorer reciprocity are among the most consistently noted features" of interactions between mothers and their children with Down syndrome (Berger, 1990 p.116). Despite these difficulties Berger (1990) argues that some successful communicative interactions do take place.

\section{Joint attention}

Joint attention is one of the most important features of social interactions (Schaffer, 1984) which involves mother and infant focusing on the same referent. Studies in the development of joint attention in infants with Down syndrome have yielded conflicting results. Given their deficit in early communicative behaviours it is not surprising that 6 months to a year old infants with Down syndrome have difficulties in attending to both toys and mothers (Landry \& Chapieski, 1989). While some researchers have shown these infants preferring to attend to mother's face as opposed to objects (Landry \& Chapieski, 1990 amongst others); others have argued the opposite (Kasari et al, 1995).

Furthermore, Ruskin et al (1994) find no significant difference in the way MA match children with Down syndrome and non-delayed infants deploy attention to both people and objects.

A study by Kasari et al (1995 p.135) concludes that the issue is not simply about attention deployment to social versus non-social stimuli. “..... children with Down syndrome have difficulty shifting attention between referents when the situation has a high cognitive load, as in the social referencing procedure. Although more social referencing was associated with cognitive and language abilities in children with typical development, more focused looking was associated with cognitive and language abilities in children with Down syndrome".

\section{Early vocabulary}

It is a well recognised fact that children with Down syndrome experience delay in expressive language (Fowler, 1990; Miller, 1988). These infants' early words are said to be similar to those produced by non-delayed children (Gillham, 1979) and emerge at the same developmental age. However, their later language acquisition lags behind their cognitive abilities (Cardoso-Martins et al, 1985). They experience particular difficulty with syntax. Gunn (1985) argues that there is no difference between the words that these children use spontaneously and those learnt earlier in imitation, but this finding is not supported by Coggins \& Morrison (1981). For a further discussion on vocabulary development see Fowler (1990). Miller (1992) shows that children with Down syndrome successfully resort to signing to compensate for their productive delay.

A number of researchers have established correlational links between pre-verbal skills and later expressive language development of children with Down syndrome (Smith et al, 1986; Mundy et al, 1988 \& 1995). It is therefore essential to examine the state of these children's prelinguistic skills in order to identify their strengths and weaknesses which could be used to facilitate their expressive development. However this needs to be done sensitively. Most of the studies have used MA as a matching index in comparing the communicative development of Down syndrome and non-delayed children, and not surprisingly most have reported an advantage in favour of the latter.

The main goal of this study is to examine and compare the prelinguistic communication abilities of young children with Down syndrome to those of non-delayed children and other children with learning disability of undefined aetiology, matched for one word comprehension level on the Derbyshire Language Scheme (Masidlover \& Knowles, 1982). The central hypothesis is that children with Down syndrome, when matched for one word comprehension level, exhibit equivalent levels of non-verbal communication skills compared to those of nondelayed infants.

\section{Method}

Ten children with Down syndrome (6 boys and 4 girls) aged between 21 and 53 months (mean CA of 35.6 months), 10 non-delayed children (5 boys and 5 girls) aged between 19 and 21 months (mean CA of 19.7 months) and 5 nonDown syndrome children ( 3 girls and 2 boys) aged between 25 and 129 months (mean CA of 
70.4 months) with learning disabilities were recruited, matched for one word comprehension level on the Derbyshire Language Scheme (Masidlover \& Knowles, 1982). None of the children with learning disabilities had any severe motor or sensory impairments. All participants were of Caucasian families with similar socio-economic backgrounds.

Data was gathered firstly by asking parents to complete "The Pragmatics Profile of Early Communication Skills", (Dewart \& Summers, 1988) a tool for assessing infants functional communication abilities. Secondly, 10 minutes samples of video recordings were made of each mother and child dyad engaged in a low structured free play situation in their own home. Procedures and methods were largely modelled on those used by Mundy et al (1988) in order to aid comparison. At the start of each session each mother and child were sat on the floor facing each other with some toys in front of them and others strategically placed around them. Those in the middle included: 1 ball, 1 puzzle, 2 dolls, 8 wooden bricks, 3 picture books, 2 small wind-up toys, 1 small hand operated toy, 1 teddy bear, 1 brush, 1 comb,
Correlations between scores of different raters were calculated to be highly significant. For instance, for one subject chosen at random the correlational coefficients were as follows:

${ }^{*}$ Rater 1 and Rater 2: $\mathrm{r}=0.9797 \mathrm{p}<0.001^{* *}$

* Rater 2 and Rater 3: $r=0.9077 \mathrm{p}<0.001^{* *}$

${ }^{*}$ Rater 1 and Rater 3: $\mathrm{r}=0.9705 \mathrm{p}<0.001{ }^{* *}$

In order to test the aforementioned hypothesis the results were analysed quantitatively using the Mann-Whitney test.

\section{Results}

\section{Part one: Questionnaire data}

Do children with Down syndrome (DS) use the same number and range of non-verbal, vocal and gestural communicative behaviours as non-delayed (ND) infants?

Maternal reports reveal no significant difference in the number and range of nonverbal, vocal and non-vocal communicative behaviours used by all three groups of children as shown in Table 1.

\begin{tabular}{|c|c|c|c|c|c|}
\hline & $\begin{array}{l}\text { Down } \\
\text { Syndrome } \\
\text { Group }\end{array}$ & $\begin{array}{l}\text { Non- } \\
\text { Delayed } \\
\text { Group }\end{array}$ & LD Group & $\begin{array}{l}\text { M-W p< } \\
\text { DS-ND }\end{array}$ & $\begin{array}{l}\text { M-W p< } \\
\text { LD-ND }\end{array}$ \\
\hline $\mathrm{N}$ & 10 & 9 & 4 & & \\
\hline Mean age (mths) & 35.6 & 19.78 & 80.7 & & \\
\hline Age range (mths) & $21-53$ & $19-21$ & $25-129$ & & \\
\hline Non-verbal & 16.90 & 15.89 & 15.00 & 0.30 & 0.43 \\
\hline Vocal & 6.00 & 6.22 & 5.00 & 0.51 & $0.0085^{* *}$ \\
\hline Gestures & 10.90 & 9.67 & 10.00 & 0.18 & 0.87 \\
\hline
\end{tabular}

Keys:M-W p <:Mann-Whitney 2 tail significance / DS-ND: Comparison between DS \& ND groups / LDND: Comparison between LD \& ND groups / ${ }^{* *}$ : $\mathrm{p}<0.01$

1 hat, 1 set of cup and saucer, 1 shape sorter and 1 doll bed. Five coloured balloons and one tractor were placed out of reach of the child but where they could be seen. Three colourful posters were each hung behind and either side of the child. The main purpose of the video recorded sessions was to capture spontaneous communicative interactions between mother and child.

Three Speech and Language Therapists were asked to rate the video recordings using a standard checklist of behaviours along with definitions provided. An average of $60 \%$ interrater agreement was obtained for all the communicative behaviours studied.
All participants used a combination of the following non-verbal behaviours: point, pull, vocalise, shout, cry, reach, raise arms, look, push away, laugh, name, make pleading noises, smile, turn away, stare, clap hands, show, imitate gestures, blow kisses, sign, nod, throw away, give, shake head, spit out, return objects, scream and other body movements. Children with a learning disability (but not Down syndrome) used significantly fewer vocal behaviours $(\mathrm{p}<0.0085)$. 
Do children with Down syndrome (DS) have the same word and total vocabulary size as nondelayed (ND) infants?

Although children with Down syndrome are reported to use half the number of words (on average) as non-delayed infants, the difference is not quite significant $(\mathrm{p}<0.07)$ here as shown in Table 2 below. recordings. The results outlined therein confirm that there is no significant difference in the average number of times children with Down syndrome and non-delayed infants used the following behaviours: smiling, shaking head, vocalising, looking at objects, looking at mother, reaching and vocalising, showing, giving, vocal imitating, turning away and clapping hands. However, it is also evident that infants with

\begin{tabular}{|llllll|}
\hline \multicolumn{6}{l}{ Table 2. Mean of word and total vocabulary } \\
& DS Group & ND Group & LD Group & $\begin{array}{l}\text { M-W } \mathbf{p}< \\
\text { DS-ND }\end{array}$ & $\begin{array}{l}\text { M-W } \mathbf{p}< \\
\text { LD-ND }\end{array}$ \\
\hline $\mathrm{N}$ & 10 & 9 & 4 & & \\
\hline Mean age (mths) & 35.6 & 19.78 & 80.7 & & \\
\hline Age range (mths) & $21-53$ & $19-21$ & $25-129$ & & 0.07 \\
\hline Word vocabulary & 11.50 & 24.11 & 10.00 & 0.07 & \\
\hline
\end{tabular}

When the mean number of signs and mean number of words are added to make up the total vocabulary of infants with Down syndrome and compared to the word vocabulary of non-delayed children, the difference, although in favour of the former, is not significant (see Table 2).

\section{Part two: video data}

Do children with Down syndrome (DS) use individual communicative behaviours as many times as non-delayed (ND) infants?

Table 3 below lists the various communicative behaviours that were studied via the video
Down syndrome are significantly delayed at using referential looking $(\mathrm{p}<0.029)$ and words $(\mathrm{p}<0.047)$; but a comparison of the total vocabulary size for these two groups yields no significant difference.

Inter-group differences between the non-delayed and the learning disability groups for most of these communicative behaviours are also not significant except for showing, reaching and vocalising, words and total vocabulary. While children in the latter group engage in significantly greater levels of reaching and vocalising, they are significantly deficient in showing and using words and have a poorer mean total vocabulary.

Table 3. Mean frequency of use of individual communicative behaviors for each group

\begin{tabular}{|c|c|c|c|c|c|}
\hline & DS & ND & LD & $\begin{array}{l}\text { M-W p< } \\
\text { DS-ND }\end{array}$ & $\begin{array}{l}\text { M-W p< } \\
\text { LD-ND }\end{array}$ \\
\hline $\mathbf{N}$ & 10 & 10 & 5 & & \\
\hline Mean age (mths) & 35.6 & 19.7 & 70.4 & & \\
\hline Smiling / Laughing & 4.30 & 3.70 & 4.80 & 0.74 & 0.17 \\
\hline Shaking Head & 0.40 & 0.90 & 1.20 & 0.37 & 0.95 \\
\hline Vocalising & 11.80 & 10.30 & 8.40 & 0.63 & 0.62 \\
\hline Looking at object & 4.70 & 9.00 & 7.20 & 0.15 & 0.76 \\
\hline Looking at mother & 8.00 & 4.50 & 3.80 & 0.18 & 0.95 \\
\hline Referential looking & 0.30 & 1.40 & 1.40 & $0.029 *$ & 0.80 \\
\hline Reaching \& Vocalising & 1.40 & 0.40 & 2.60 & 0.07 & $0.0516^{*}$ \\
\hline Showing & 0.80 & 2.10 & 0.20 & 0.11 & $0.0249 *$ \\
\hline Giving & 3.20 & 3.70 & 2.80 & 0.72 & 0.19 \\
\hline Vocal imitating & 1.60 & 2.80 & 1.20 & 0.28 & 0.17 \\
\hline Turning away & 1.00 & 1.50 & 3.00 & 0.64 & 0.36 \\
\hline Clapping hands & 1.60 & 0.50 & 0.20 & 0.19 & 0.93 \\
\hline Signing & 1.50 & 0.00 & 0.00 & $0.046^{\star}$ & 1.00 \\
\hline Words & 4.80 & 9.80 & 1.20 & $0.047^{*}$ & $0.0046^{* *}$ \\
\hline Total Vocabulary & 5.90 & 7.89 & 1.40 & 0.35 & $0.0054^{* *}$ \\
\hline
\end{tabular}


Is there a correlation between results obtained via the questionnaire and video recording?

The figures in Table 4 below show that there are significantly high levels of correlations for words and signs between maternal reports and the video data.
Fischer's (1987) earlier observations that infants with Down syndrome use gestures such as clapping hands, giving and shaking head to the same extent as non-delayed children. Since the differences between the learning disability and non-delayed groups for these behaviours are also non-significant it cannot be inferred that these

\section{Table 4. Correlations between maternal reporting and video observations of words and sign.}

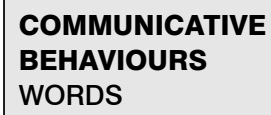

$M-W \mathbf{p}<$

$0.01 *$ (Sig.) abilities of Down syndrome children are specific to them.

The present study also finds nonsignificant differences between the Down syndrome and non-delayed groups in the use of giving and showing which is borne out by Greenwald \& Leonard (1979) who

\section{Discussion}

It is remarkable how well children with Down syndrome are shown to match the control group of non-delayed infants in their ability to communicate intentionally. The results are well supported by earlier findings, for instance, by Coggin et al (1983) who compared their participants on sensorimotor level and MLU. However, the study also reveals important differences in performance by the two groups but these are few and far between.

As mentioned earlier, when matched for comprehension children with Down syndrome are as able as non-delayed infants in their use of non-verbal $(\mathrm{p}<0.301)$, vocal $(\mathrm{p}<0.511)$ and gestural $(\mathrm{p}<0.1800)$ communicative behaviours (see Table 1 above). With the inclusion of a third control group in this study it becomes clear that children with learning disabilities are significantly more deficient at using vocal behaviours $(\mathrm{p}<0.0085)$ than the other two groups of children. Thus the similarity of the mean frequency score of the use of vocal behaviours between the non-delayed and Down syndrome group can be interpreted as the effect of Down syndrome.

The above findings contradict the popular belief that young children with Down syndrome use gestures significantly more than vocal means to communicate with, which has been reported by studies mostly using mental age or sensorimotor level as matching measures (Greenwald \& Leonard, 1979). However, as pointed out by McCune et al (1986, pl16) a closer examination of this issue shows that "in young home-reared children the gesture advantage was due to comparatively lower vocalisation rates rather than general advance in and preference for gesture".

In analysing the actual rates of communicative behaviours reported in the video data (see Table 3 above) it is apparent that the results support report in favour of the former. Mundy et al (1988) report that children with Down syndrome use giving as a means of requesting significantly more than their MA matched nondelayed counterpart while there is no significant difference in the way they use showing to indicate.

Furthermore, there appears to be no difference in the extent to which non-delayed and Down syndrome children use reaching and vocalising. As the mean scores for showing and reaching and vocalising between the non-delayed and the learning disability group are significant $(\mathrm{p}<0.0249 \& \mathrm{p}<0.05$ respectively), the above findings could be attributed to the effect of having Down syndrome.

In contrast to previous studies (e.g. Landry \& Chapieski, 1989) which argue that infants with Down syndrome are more deficient at looking at their mothers and other stimuli compared to MA matched non-delayed children, the present results show no significant difference. Although children with Down syndrome on average look at their mothers more often than they do at objects while non-delayed infants do the opposite, these differences too are, contrary to Landry \& Chapieski's (1990) findings, not significant here. Furthermore both of these results of the present study are borne out by Ruskin et al (1994) from their investigation into these issues using MA matched children.

The study also confirms Jones' (1977) earlier findings that infants with Down syndrome use referential eye contact significantly less $(\mathrm{p}<0.029)$ than non-delayed children.

While most studies describe the affective as dull, neutral and deficient, (Buckhalt et al, 1978, amongst others), the present study reports no significant difference in their frequency of responsiveness of infants with Down syndrome 
smiling compared to non-delayed children matched for verbal comprehension level. A more recent study by Knieps et al (1994) lends some support to this result by suggesting that on the whole the affective responsiveness of toddlers with Down syndrome is similar to that of MA matched non-delayed children except for their inability to match their parents affective expressions.

Children with Down syndrome have been shown to vocalise to the same extent as non-delayed infants here and this appears to be in agreement with other findings such as those of Smith \& Oller (1981) and Steffens et al (1992).

However, contrary to Mahoney et al, (1981) the mean frequency of vocal imitation of infants with Down syndrome is reported to be equivalent to that of non-delayed children.

On the one hand the present study confirms Miller et al's (1987) and Cardoso-Martins et al's (1985) findings that infants with Down syndrome are significantly delayed at using words $(\mathrm{p}<0.047)$ and on the other, it contradicts Rondal's (1978) study which matched its participants on both MA and MLU. What is clear is that in order to compensate for this expressive deficit children with Down syndrome resort to signing $(\mathrm{p}<0.46)$ successfully. This is supported by the fact that when the total vocabulary (words and signs together) of infants with Down syndrome is compared to the word vocabulary of non-delayed children, the difference is not significant $(\mathrm{p}<0.353)$ which confirms Miller et al's (1991) earlier observation. This result reiterates the importance of early sign training for children with Down syndrome

This study has attempted to demonstrate that infants with Down syndrome are as competent as non-delayed children matched for one word comprehension level at using prelinguistic communication skills with the exception of referential eye contacts and words. However, these results may not be as conclusive as they appear for a number of reasons. In the first place, most of these abilities of children with Down syndrome highlighted above may not be specific to them. This is because for most of the communicative behaviours studied here, the differences in mean scores between the nondelayed and the learning disability groups are also not significant. This phenomenon is the result of a considerably higher mean chronological age of the learning disability group.

Another reason why these results must be interpreted with some caution is that the sample size is small and not even across the three groups, a factor which may affect statistical analyses. A further problematic issue is that the communicative behaviours studied here yielded an average of $60 \%$ interrater agreement between the raters.

\section{Conclusion}

Nevertheless, the study clearly shows that children with Down syndrome have a good grasp of the early prelinguistic skills which must be viewed as their strengths particularly for the hypothesised link between this stage and later language development. For instance, Mundy et al (1988 \& 1995) and Smith \& Tetzchner (1986) have found that non-verbal requesting for objects is associated with later language development. Further data analyses are required to ascertain whether or not the above correlations are borne out by this study. Interventions aimed at further improving such non-verbal skills in children with Down syndrome may prove useful at remediating the expressive language deficit they experience.

Future research should adopt a longitudinal design in order to map out the transition from preverbal to language skills in children with Down syndrome in an effort to shed more light on the relationship between these two stages of development.

\section{Acknowledgements}

The authors would like to thank all parents and children who took part in the study, the speech and language therapists for their help and Rebecca Stores and Mike Fluck (University of Portsmouth) for their helpful comments.

\section{Correspondence:}

B. Ramruttun. Senior Manager. Community Learning Disability Nursing Service. Winchester and Eastleigh Healthcare NHS Trust. Andover Community Specialist Team. Andover Health Centre. Charlton Road. Andover. Hampshire. SP10 3TB. United Kingdom.

(E-mail:WEHCLDBR@hantsnet.hants.gov.uk).

Author Note: This paper was presented as a poster at the 2nd International Conference on Language and Cognitive Development in Down Syndrome, 8-10 April, 1997, Portsmouth, UK. 


\section{References}

Bates, E., Camaioni, L. \& Volterra, V. (1975). The acquisition of performatives prior to speech. Merrill-Palmer Quarterly, 21 (3), 205-226.

Berger, J. (1980). Early development of social signalling, attentional and communicative behaviours in Down syndrome and non-retarded infants. Unpublished Doctoral Dissertation. University of Manchester.

Berger, J. (1990). Interactions between parents and their infants with Down syndrome. In D. Cicchetti \& M Beeghly (Eds.), Children with Down Syndrome: A Developmental Perspective. Cambridge: Cambridge University Press.

Berger, J. \& Cunningham, C. (1983). The development of early vocal behaviours and interactions in Down syndrome and non-handicapped infant-mother pairs. Developmental Psychology, 19, 322-331.

Buckhalt, J., Rutherford, R. \& Goldberg, K. (1978). Verbal and non-verbal interaction on mothers with their Down syndrome and non-retarded infants. American Journal of Mental Deficiency, 82, 337-343.

Bruner, J. S. (1983). Child's talk: learning to use language. Oxford: Oxford University Press.

Cardoso-Martins, C. \& Mervis, C. (1985). Maternal speech to prelinguistic children with Down syndrome. American Journal of Mental Deficiency, 89, 451-458.

Chomsky, N. (1959). Review of verbal behaviour, by B.F. Skinner. Language, 35, 26-58.

Coggins, T., Carpenter, R. \& Owings, N. (1983). Examining early intentional communication in Down's syndrome and non-retarded children. British Journal of Disorders of Communication, 18, 98106.

Coggins, T. \& Morrison, J. (1981). Spontaneous initiations of Down's syndrome children: a lexical analysis. Journal of Speech and Hearing Research, 46, 303-308.

Courage, M., Adams, R., Reyno, S. \& Kwa, P. (1994). Visual acuity in infants and children with Down Syndrome. Developmental Medicine and Child Neurology. 36, 586-593.

Crown, L., Feldstein, S., Jasnow, M., Beebe, B. \& Jaffe, J. (1992). Down's syndrome infant gaze. Acta Paedopsychiatrica. 55, 511-555.

Dewart, H. \& Summers, S. (1988). "The Pragmatics Profile of Early Communication Skills". Windsor: NFER-Nelson.

Dodd, B. (1972). Comparison of babbling patterns in normal and Down-syndrome infants. Journal of Mental Deficiency Research, 16, 35-40.

Fantz, R., Fagan, J. \& Miranda, S. (1975). Early visual selectivity as a function of pattern variables, previous exposure, age from birth and conception, and expected cognitive deficit. In L. Cohen \& P. Salapatek (Eds.), Infant Perception. New York: Academic Press.

Fischer, M. (1987). Mother child interaction in pre-verbal children with Down syndrome. Journal of Speech and Hearing Disorders, 52, 179-190.

Fogel, A. (1993). Two principles of communication: coregulation and framing. In J. Nadel \& L. Camaioni (Eds.), New Perspectives in Early Communication Development. London: Routledge.

Fowler, A. (1990). Language abilities in children with Down syndrome: Evidence for specific syntactic delay. In D. Cicchetti \& M. Beeghly (Eds.), Children with Down Syndrome: A Developmental Perspective. Cambridge: Cambridge University Press.

Gillham, B. (1979). The First Words Programme. London: Allen \& Unwin.

Greenwald, C. \& Leonard, L. (1979). Communicative and sensorimotor motor development of Down's syndrome children. American Journal of Mental Deficiency, 84, 296-303.

Gunn, P. (1985). Speech and language. In Lane, D. \& Stratford, B. (Eds.), Current Approaches to Down's Syndrome. Cassell.

Jones, O. (1977). Mother child communication with prelinguistic Down's syndrome and normal infants. In R. Schaffer (Ed.), Studies in Mother-Infant Interaction. New York: Academic Press. 
Kasari, C., Mundy. P., Yirmiya, N. \& Sigman, M. (1990). Affect and attention in children with Down syndrome. American Journal on Mental Retardation, 95, 55-67.

Kasari, C., Freeman, S., Mundy, P. \& Sigman, M. (1995). Attention regulation by children with Down syndrome: co-ordinated joint attention and social referencing looks. American Journal on Mental Retardation. 100 (2), 128-136.

Knieps, L., Walden, T. \& Baxter, A. (1994). Affective expressions of toddlers with and without Down syndrome in a social referencing context. American Journal on Mental Retardation. 99 (3), 301-312.

Landry, S. \& Chapieski, M. (1989). Joint attention and infant toy exploration: Down Syndrome and pre-maturity. Child Development, 60, 103-118.

Landry, S. \& Chapieski, M. (1990). Joint attention of six-month-old Down syndrome and pre-term infants: attention to toys and mother. American Journal on Mental Retardation, 94, 488-498.

Lenneberg, E. (1967). Biological foundation of language. New York: Wiley. (Cited in J. Berger, 1980, OP.CIT)

Lynch, M., Offer, K., Steffens, M., Levine, S., Basinger, D. \& Umbel, V. (1995). Onset of speech like vocalisation in infants with Down syndrome. American Journal on Mental Retardation, 100 (1), 6886.

Mahoney, G., Glover, A., \& Finger, L. (1981). Relationship between language and sensorimotor development of Down syndrome and nonretarded children. American Journal of Mental Deficiency, 87, 86-95.

Masidlover, M., \& Knowles, W. (1982). The Derbyshire Language Scheme. Derby: Derbyshire County Council.

Miller, J. (1988). The developmental asynchrony of language development in children with Down's syndrome. In Nadel, L. (Ed.), The Psychobiology of Down Syndrome. MIT Press.

Miller, J. (1992). Lexical development in young children with Down syndrome. In R. Chapman (Ed.), Processes in Language Acquisition and Disorders. MA: Mosley Yearbook.

Miller, J. (1992). Development of speech and language in children with Down syndrome. In T. Lott, \& E. McCoy. (Eds.), Down Syndrome: Advances in Medical Care. London: Wiley.

Miller, J., Sedey, L., Miolo, G., Rosin, M., \& Murray-Branch, J. (1991). Spoken and sign vocabulary acquisition in children with Down syndrome. Asha Convention, Atlanta, Georgia, November.

Mundy, P., Sigman, M., Kasari., \& Yirmiya, N. (1988). Non-verbal communication skills in Down syndrome children. Child Development, 59, 235-249.

Mundy, P., Kasari, C., Sigman, M. \& Ruskin, E. (1995). Non-verbal communication and early language acquisition in children with Down's syndrome and in normally developing children. Journal of Speech and Hearing Research, 38, 157-167.

Rondal, J. (1978). Developmental sentence procedure and the delay-difference question in language development of Down's syndrome children. Mental Retardation, 16, 169-171.

Rondal, J. (1985). Linguistic and prelinguistic development in moderate and severe mental retardation. In J. Dobbing et al (Eds.), Scientific Studies in Mental Retardation. London: Macmillan Press.

Ruskin, M., Mundy, P., Kasari, C., \& Sigman, M. (1994). Object mastery motivation of children with Down syndrome. American Journal on Mental Retardation, 98 (4), 499-509.

Schaffer, R. (1984). The child's entry into a social world. London: Academic Press.

Smith, B. \& Oller, K. (1981). A comparative study of pre-meaningful vocalisations produced by normally developing and Down's syndrome infants. Journal of Speech and Hearing Disorders, 46, 4651 . 
Smith, L. \& Von Tetzchner, S. (1986). Communicative, sensorimotor, and language skills of young children with Down syndrome. American Journal of Mental Deficiency, 91 (1), 57-66.

Sorce, J. F. \& Emde, R. N. (1982). The meaning of the infant emotional expressions : Regularities in care giving responses in normal and Down Syndrome infants. Journal of Child Psychology and Psychiatry, 22, 145-158.

Steffens, M., Oller, K., Lynch, M. \& Urano, R. (1992). Vocal development in infants with Down syndrome and infants who are developing normally. American Journal on Mental Retardation, 97 (2), 235-246.

Vygotsky, L. (1986). Thought and language (2nd ed.), Cambridge, MA: MIT Press.

Woodhouse, J., Pakemau, U., Saunders, K., Parker, M., Fraser, W., Lobo, S. \& Sastry. P. (1996). Visual activity and accommodation in infants and young children with Down syndrome. Journal of Intellectual Disability Research. 4 (1), 49-55. 